\title{
Metabolic Protein Patterns and Monascorubrin Production Revealed through Proteomic Approach for Monascus pilosus Treated with Cycloheximide
}

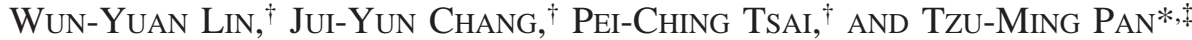 \\ Department of Food Science, Nutrition and Nutraceutical Biotechnology, Shih Chien University, \\ Taipei, Taiwan, and Institute of Microbiology and Biochemistry, National Taiwan University, \\ Taipei, Taiwan, Republic of China
}

\begin{abstract}
Monascus species have the unique ability to economically produce many secondary metabolites. However, most metabolic regulation processes in the production of secondary metabolites in Monascus remain unclear. We found that the translational inhibitor cycloheximide induced different expression patterns between the monascorubrin pigment production and the growth in Monascus pilosus. Here, we used the proteomic approach of two-dimensional gel electrophoresis, matrix-assisted laser desorption ionization time-of-flight/time-of-flight liquid chromatography-mass spectrometry (MALDITOF/TOF LC-MS), and tandem mass spectrometry (MS/MS) to identify the intracellular and mitochondrial proteins of $M$. pilosus between the cycloheximide treatment and the control. These results revealed that the cycloheximide-induced down-regulated proteins were involved in transcriptional regulation, peptide synthesis, and other metabolic processes, such as methylation of secondary metabolites. In contrast, the energy-related proteins, such as the transcriptional regulator rosAr and $1,4-\alpha$-glucan branching enzyme, were up-regulated as compared to the control.
\end{abstract}

KEYWORDS: Monascus pilosus; food pigments; cycloheximide; proteome

\section{INTRODUCTION}

Monascus species are extensively used on fermented foods and in folk medicine and have been for thousands of years in China. There are many scientific reports on the medical or functional food effects in Monascus red mold rice $(1,2)$. Monascus produces many types of polyketide secondary metabolites with an enormous commercial value and many functional properties, including a group of yellow, orange, and red pigments (3), monacolin $\mathrm{K}$ (also known as lovastatin, a potent competitive inhibitor of 3-hydroxy-3-methylglutaryl coenzyme A reductase as an antihypercholesterolemic agent), and an antibacterial compound citrinin $(4,5)$. Polyketides are a structurally diverse and complex group of secondary metabolites with a broad range of biological activities $(6,7)$. Their biosynthesis, by using acetyl-CoA as the building block, is involved in multiple enzyme systems and pathways, including polyketide synthases (PKS), biosynthesis of their precursors, precursor-regulated pathways, and modification of intermediate reaction $(6,8)$. However, many of the metabolic regulation processes in the biosynthesis of secondary metabolites in Monascus remain unclear. There are many challenges in understanding how Monascus regulates cellular mechanism in the biosynthesis of secondary metabolites during fermentation.

The key technologies of the proteome analysis are protein separation by two-dimensional electrophoresis (2-DE) and mass

\footnotetext{
Shih Chien University.

$\$$ National Taiwan University.
}

spectrometric protein identification, which result in the efficient analysis of hundreds of proteins expressed in cells at one time. Proteomics allows the profiling of the expression patterns of proteins involved in metabolic pathways and also helps to directly discern the biology of cells at the protein species level and the protein composition change under different conditions. However, as compared to bacteria, plant, and animal analyses, only very few studies on 2-DE proteomics of filamentous fungi are reported (9). Proteomics in filamentous fungi is still at a relatively early stage of development, particularly of intracellular and mitochondrial proteins (9). The unique characteristics of Monascus in the biosynthesis of secondary metabolites deserve our attention. Therefore, we conducted this proteomic study for the identification and quantification of Monascus proteins.

Cycloheximide (CHX) is one of the antibiotics inhibiting protein synthesis translation in most eukaryotic cells, including Saccharomyces cerevisiae and Aspergillus niger (10). CHX treatment, which blocks elongation of the nascent polypeptide chain in ribosomes, may cause metabolic stress and stimulate general stress response pathways in cells. In this work, we found that translational inhibitor CHX treatment induced different expression patterns between the biosynthesis of secondary metabolite pigment monascorubrin (MBN) and the growth mass in Monascus pilosus BCRC 31527 during fermentation. The aim of this work is to characterize the CHX-induced protein profiles in the MBN formation-blocked cultivated cells and to extend our understanding of the regulation mechanism of Monascus in secondary metabolite biosynthesis. Our approach 
compared protein expression patterns between the CHX-treated and the control in M. pilosus and used 2-DE and matrix-assisted laser desorption ionization time-of-flight/time-of-flight liquid chromatography-mass spectrometry (MALDI-TOF/TOF LCMS). Database searches to identify metabolic proteins were performed. In this work, the resulting data revealed that the CHX-induced deregulation proteins were implicated in glycolysis, gluconeogenesis/energy production, peptide translation synthesis, and transcription regulation, such as transcriptional regulator nanR (NanR) and transcriptional regulatory protein rosAr (RosAr).

\section{MATERIALS AND METHODS}

Microorganism and Growth Conditions. The strain of M. pilosus BCRC 31527 used was a high pigment-producing strain, in a previous study (11), and was obtained from the Bioresource Collection and Research Center (BCRC) in Taiwan. Monascus was sporulated and maintained on potato dextrose agar (Merck, Darmstadt, Germany) in stock culture. The growth medium for biosynthesis of MBN was glucose nitrate medium consisting of $3 \% \mathrm{w} / \mathrm{v}$ glucose, $0.15 \% \mathrm{w} / \mathrm{v} \mathrm{NaNO}_{3}, 0.1 \%$ w/v $\mathrm{MgSO}_{4} \cdot 7 \mathrm{H}_{2} \mathrm{O}$, and $0.25 \%$ w/v $\mathrm{KH}_{2} \mathrm{PO}_{4}$ following the method of previous studies (12). The spores were prepared by growth on potato dextrose agar slants for 15 days at $32{ }^{\circ} \mathrm{C}$ and were washed with a sterile phosphate buffer (50 mM, pH 7.0). In cultivation, a suspension of $10^{8}$ spores was used to inoculate a $1 \mathrm{~L}$ baffled Erlenmeyer flask containing $250 \mathrm{~mL}$ of glucose nitrate medium (the $\mathrm{pH}$ of the medium was adjusted to 6.2 with $1 \mathrm{~N} \mathrm{HCl}$ or $1 \mathrm{~N} \mathrm{NaOH}$ before sterilization) for the control and the treatments, respectively, which were then cultivated at $32{ }^{\circ} \mathrm{C}$ for 10 days in submerged fermentation on a rotary shaker at $150 \mathrm{rpm}$ in triplicate. To inhibit protein synthesis in cells, the treatments were performed by adding $0.5 \mathrm{~mL}$ of stock solution of CHX (Sigma) to the treated media at the first, second, third, fourth, and fifth days of cultivation, respectively, to the final concentration of $10 \mu \mathrm{g} / \mathrm{mL}$ (see Figure 1).

Reagents and Materials. One hundred mesh cadmium was purchased from Aldrich (Milwaukee, WI). The 2-DE reagents including acrylamide solution (25\%), dithiothreitol (DTT), sodium dodecyl sulfate (SDS), trifluoroacetic acid (TFA), urea, iodoacetamide (IAA), thiourea, 3-[(3-cholamidopropyl) dimethylammonio]-1-propane sulfonate (CHAPS), Immobiline Dry Strips, immobilized pH gradients (IPG) buffer, IPG cover mineral oil, Tris base, and protein assay kit were purchased from Bio-Rad (Hercules, CA). CHX, sulfanilamide, $N$-(1-naphthyl) ethylenediamine dihydrochloride, phenylmethanesulfonyl fluoride (PMSF), sorbitol, $N$-(2-hydroxyethyl) piperazine- $N$-(2-ethanesulfonic acid) potassium salt (HEPES-KOH), and $\alpha$-cyano-4-hydroxycinnamic acid (CHCA) were purchased from Sigma (St. Louis, MO). Sypro Ruby stain was purchased from Amersham Biosciences (Piscataway, NJ). Trypsin (modified) was obtained from Promega (Madison, WI). ZipTip C18 microcolumns were purchased from Millipore (Bedford, MA). Other reagents used in this work were of analytical grade and were purchased from local suppliers.

Assay Methods of Pigment MBN Production and Residual Nitrate Content. Measurement of pigment MBN production was performed as described $(3,12)$. Briefly, after fermentation, the mycelia from each flask were filtered and washed with distilled water. The washed mycelia were extracted with $80 \mathrm{~mL}$ of $95 \%$ ethanol for $12 \mathrm{~h}$. The filtered solution and extract were made into aliquots $(100 \mathrm{~mL})$ with a volumetric flask, and the absorbance at $470 \mathrm{~nm}$ was measured in a spectrophotometer (Thermo Helios $\alpha$, Waltham, MA). The two values were added to give the total absorbance of MBN production. To determine the residual nitrate content in the growth media, we used the acidic Griess reaction for color development according to the previous study (13). In this procedure, after centrifugation of the culture broth at $5000 \mathrm{~g}, 4^{\circ} \mathrm{C}$ for $10 \mathrm{~min}, 0.5 \mathrm{~mL}$ of the supernatants or nitrate standards was added to a test tube to which a $2 \mathrm{~mL}$ carbonate buffer (50 mM, pH 9.0) was added, followed by an amount $(0.75 \mathrm{~g})$ of cadmium alloy filings prepared as described (13). The tubes were then incubated at room temperature for $1 \mathrm{~h}$ with thorough shaking for the reduction of nitrate with cadmium alloy and deproteinization. The reaction was stopped with the addition of $0.5 \mathrm{~mL}$ of $0.35 \mathrm{~N} \mathrm{NaOH}$, followed by $2 \mathrm{~mL}$ of $120 \mathrm{mM}$ zinc sulfate solution under vortex, and the solution was allowed to stand for $10 \mathrm{~min}$. The tubes were centrifuged at $4000 \mathrm{~g}$ for $10 \mathrm{~min}$. A half milliliter of the clear supernatant was transferred to another test tube, and $250 \mu \mathrm{L}$ of $1.0 \%$ sulfanilamide (prepared in $3 \mathrm{~N} \mathrm{HCl}$ ) and $250 \mu \mathrm{L}$ of $0.1 \% \mathrm{~N}$-(1-naphthyl) ethylenediamine (prepared in water) were added with shaking. After $10 \mathrm{~min}$, the amount of absorbance was measured at $545 \mathrm{~nm}$ against a blank (Thermo Helios $\alpha$ ). For cell growth mass, the mycelia after extraction were lyophilized in a vacuum-freeze dryer (EYELA FDU-540, Tokyo, Japan) for 2 days.

Preparation of Intracellular and Mitochondrial Protein Extracts for 2-DE. The Monascus cultivated cells (from the third day's CHX treatment culture after 6 days of cultivation; see Figure 1) were washed twice with $50 \mathrm{mM}$ phosphate buffer $(\mathrm{pH} 7.0)$ after centrifugation of the culture broth at $20000 \mathrm{~g}$ and $4{ }^{\circ} \mathrm{C}$, and the cell pellets were stored at $-70{ }^{\circ} \mathrm{C}$ for further analysis. Preparation of intracellular proteins for 2-DE was performed as described (11). Briefly, proteins were extracted in a Tris- $\mathrm{HCl}$ buffer, after sonication and disruption with a continuous type presser (Constant Systems Ltd., Northants, England). After centrifugation at $40000 \mathrm{~g}$ and $4{ }^{\circ} \mathrm{C}$ to obtain the supernatant, the resulting supernatant was mixed with ice-cold trichloroacetic acid and DTT and was incubated at $-20{ }^{\circ} \mathrm{C}$ overnight. After centrifugation at $7000 \mathrm{~g}$ for $30 \mathrm{~min}$ at $4{ }^{\circ} \mathrm{C}$, the pellets were washed with ice-cold acetone containing $0.1 \% \mathrm{w} / \mathrm{v}$ DTT to obtain the cellular protein pellets. The mitochondrial protein extracts were isolated from the cellular protein pellets according to a previously published procedure (14). The $500 \mathrm{mg}$ cellular protein pellet was resuspended in $2 \mathrm{~mL}$ of SHP buffer $(600 \mathrm{mM}$ sorbitol, $20 \mathrm{mM}$ HEPES-KOH, pH 7.4, and $1 \mathrm{mM}$ PMSF) and spun at $600 \mathrm{~g}$ for $10 \mathrm{~min}$ at $4{ }^{\circ} \mathrm{C}$. The supernatant was collected and recentrifuged at $10000 \mathrm{~g}$ for $10 \mathrm{~min}$ at $4{ }^{\circ} \mathrm{C}$ to pellet the mitochondrial fraction. The pellets were washed with $2 \mathrm{~mL}$ of SHP buffer and spun at $10000 \mathrm{~g}$ for $10 \mathrm{~min}$ at $4{ }^{\circ} \mathrm{C}$ to obtain the mitochondrial protein pellets.

2-DE of Cellular and Mitochondrial Proteins, Image Analysis, and In-Gel Digestion. Protein separation by isoelectric point was performed with an isoelectric focusing system (IPGphor; Amersham Biosciences). Immobiline Dry Strips (13 cm, nonlinear pH 3-10; Amersham Biosciences) were rehydrated for $12 \mathrm{~h}$ at room temperature in a rehydration buffer ( $7 \mathrm{M}$ urea, $4 \% \mathrm{w} / \mathrm{v}$ CHAPS, and a trace of bromophenol blue). The hydrated strip containing $300 \mu \mathrm{g}$ of protein sample was kept at $20^{\circ} \mathrm{C}$ on an electric field programmed as follows: $100 \mathrm{~V}$ for $1 \mathrm{~h}, 250 \mathrm{~V}$ for $1 \mathrm{~h}, 500 \mathrm{~V}$ for $1 \mathrm{~h}, 1000 \mathrm{~V}$ for $1 \mathrm{~h}, 4000 \mathrm{~V}$ for $1 \mathrm{~h}$, and $8000 \mathrm{~V}$ for $50000 \mathrm{~V} / \mathrm{h}$; total, $55970 \mathrm{~V} / \mathrm{h}$. The IPG gel strip was incubated for $15 \mathrm{~min}$ in $50 \mathrm{mM}$ Tris- $\mathrm{HCl}$ buffer (pH 8.8) containing $6 \mathrm{M}$ urea, $30 \% \mathrm{v} / \mathrm{v}$ glycerol, $2 \% \mathrm{w} / \mathrm{v}$ SDS, and $2 \% \mathrm{v} / \mathrm{v}$ DTT, followed by equilibration for $15 \mathrm{~min}$ in the same solution containing $2.5 \% \mathrm{w} / \mathrm{v}$ IAA instead of DTT. Separation of proteins by $M_{\mathrm{r}}$ was carried out in a $10 \%$ polyacrylamide gel $1.5 \mathrm{~mm}$ thick with a horizontal SDSpolyacrylamide gel electrophoresis (PAGE) system $(13.5 \mathrm{~cm} \times$ $13.5 \mathrm{~cm}$, Protean II xi Cell; Bio-Rad) at a constant voltage of $10 \mathrm{~mA}$ for $0.5 \mathrm{~h}$ and $30 \mathrm{~mA}$ for $4 \mathrm{~h}$. Sypro Ruby stain was used for visualization of the 2-DE gel. Sypro Ruby-stained gels were digitized using a computing densitometer (Typhoon 9200 scanner, Amersham Biosciences) and analyzed with PDQuest software (Bio-Rad). Protein spots were enumerated, quantified, and characterized with respect to their molecular mass and isoelectric point by bilinear interpolation between landmark features on each image previously calibrated with respect to internal 2-DE standards (Bio-Rad). The gel spots of interest were manually excised from the gels using biopsy punches. Proteins selected for analysis were in-gel reduced, alkylated, and digested with trypsin. Briefly, spots were washed twice with water, shrunk for 15 min with $50 \% \mathrm{v} / \mathrm{v}$ acetonitrile $(\mathrm{ACN})$, and dried in a Savant Speed Vac (SC $110 \mathrm{~A}$ ) for $30 \mathrm{~min}$. Then, the samples were reduced with $10 \mathrm{mM}$ DTT in $25 \mathrm{mM}$ ammonium bicarbonate for $30 \mathrm{~min}$ at $55^{\circ} \mathrm{C}$ and subsequently alkylated with $55 \mathrm{mM}$ IAA in $25 \mathrm{mM}$ ammonium bicarbonate for 20 min in the dark. Finally, samples were digested with $12.5 \mathrm{ng} / \mathrm{mL}$ sequencing-grade trypsin in $25 \mathrm{mM}$ ammonium bicarbonate $(\mathrm{pH} 8.5)$ for at least $6 \mathrm{~h}$ at $37^{\circ} \mathrm{C}$.

Amino Acid Sequencing by MALDI-TOF/TOF MS and LC-MS. Analysis of peptides generated by in-gel digestion was performed with an Applied Biosystems 4700 Proteomics Analyzer mass spectrometer 

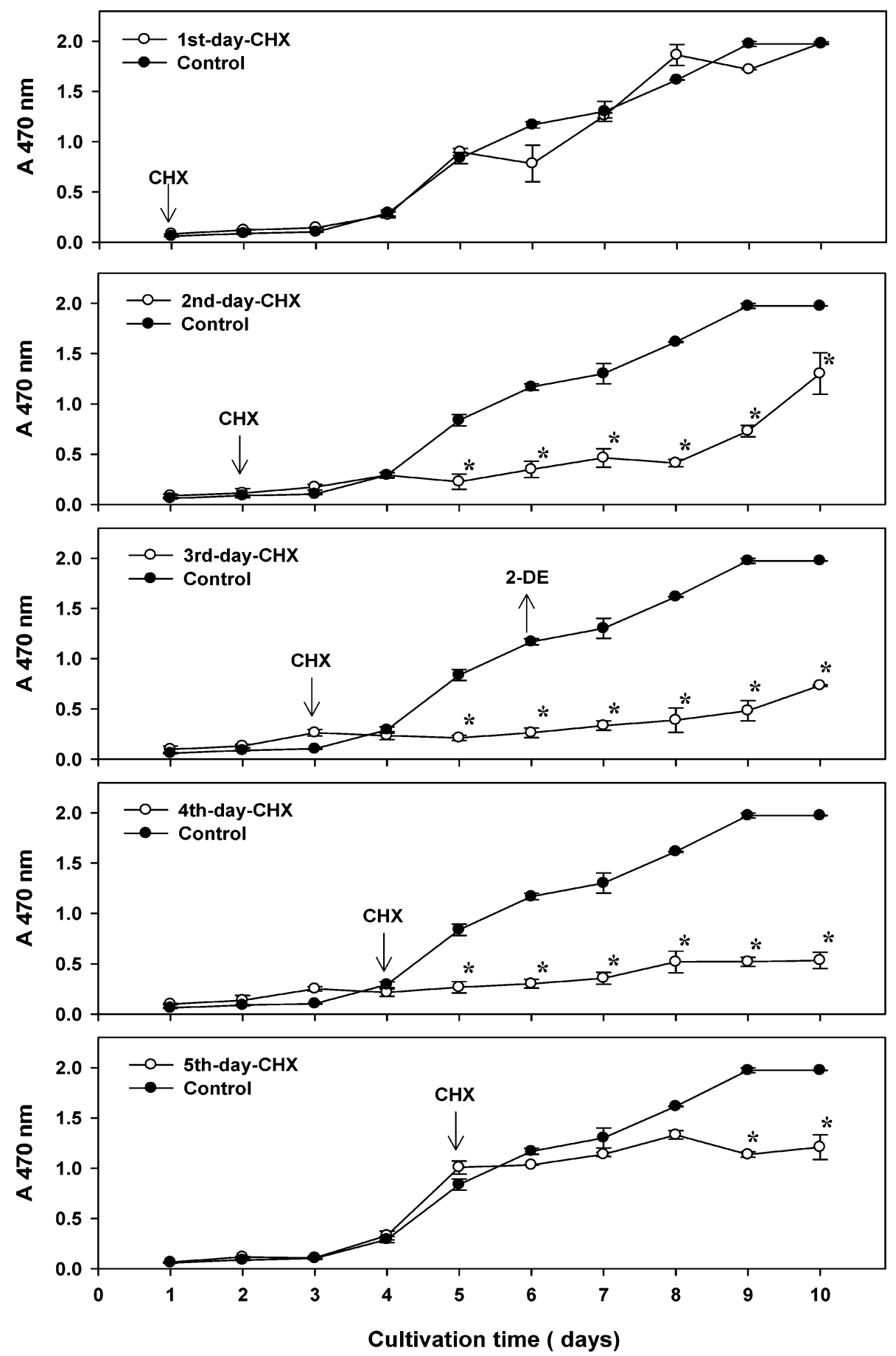

Figure 1. Effect of $\mathrm{CHX}$ addition ( $10 \mu \mathrm{g} / \mathrm{mL}$ in the medium) on the different days (the first to fifth days) of treatment on the MBN production (absorbance, $A=470 \mathrm{~nm}$ ) in batch type of submerged fermentation of $M$. pilosus BCRC 31527 during culture development on a rotary shaker at $32{ }^{\circ} \mathrm{C}$ and $150 \mathrm{rpm}$ for 10 days. Results are presented as means \pm standard deviations for three independent analyses. An asterisk indicates values at each day that were significantly different from the controls (Student's $t$ test; $P<0.05$ ). $\mathrm{CHX}$, the day of $\mathrm{CHX}$ addition; 2-DE, the day that the cells were harvested and proteins were extracted for 2-DE gel analysis.

(Applied Biosystems, Framingham, MA) equipped with an Nd:YAG laser ( $355 \mathrm{~nm}$ wavelength, $<500 \mathrm{ps}$ pulse, and $200 \mathrm{~Hz}$ repetition rate). The tryptic-digested peptide samples were premixed with a $5 \mathrm{mg} / \mathrm{mL}$ matrix solution of $\mathrm{CHCA}$ and dissolved in $50 \% \mathrm{ACN}$ with $0.1 \%$ formic acids. The indicated collision cell pressure was increased from $3.0 \times$ $10^{-8}$ Torr (no collision gas) to $5.0 \times 10^{-7}$ Torr. MS data were acquired using the instrument internal calibration. At a resolution above 10000 in MS mode, accurate mass measurement ( $<50 \mathrm{ppm}$ ) of the monoisotopic isopeptide signals was possible. To identify the protein, all MS, MS/MS, and LC-MS spectra of tryptic peptides derived from a protein spot were searched against protein sequences from the SwissPort, NCBI, and/or MSDB databases using MASCOT (http://www.matrixscience- .com) in the parameters: fungi and bacteria taxonomy category; peptide mass tolerance, $50 \mathrm{ppm}$.

\section{RESULTS}

CHX Induced Different Expression between the MBN Production and the Growth Mass during Fermentation. $\mathrm{CHX}$ is an antibiotic that inhibits the peptidyl elongation reaction on the ribosome by binding specifically to the 60S large subunit, and it has been used widely for studies involving inhibition of eukaryotic protein synthesis during translation $(10,15)$. In the literature, wild-type strains of $S$. cerevisiae are sensitive to $\mathrm{CHX}$ 


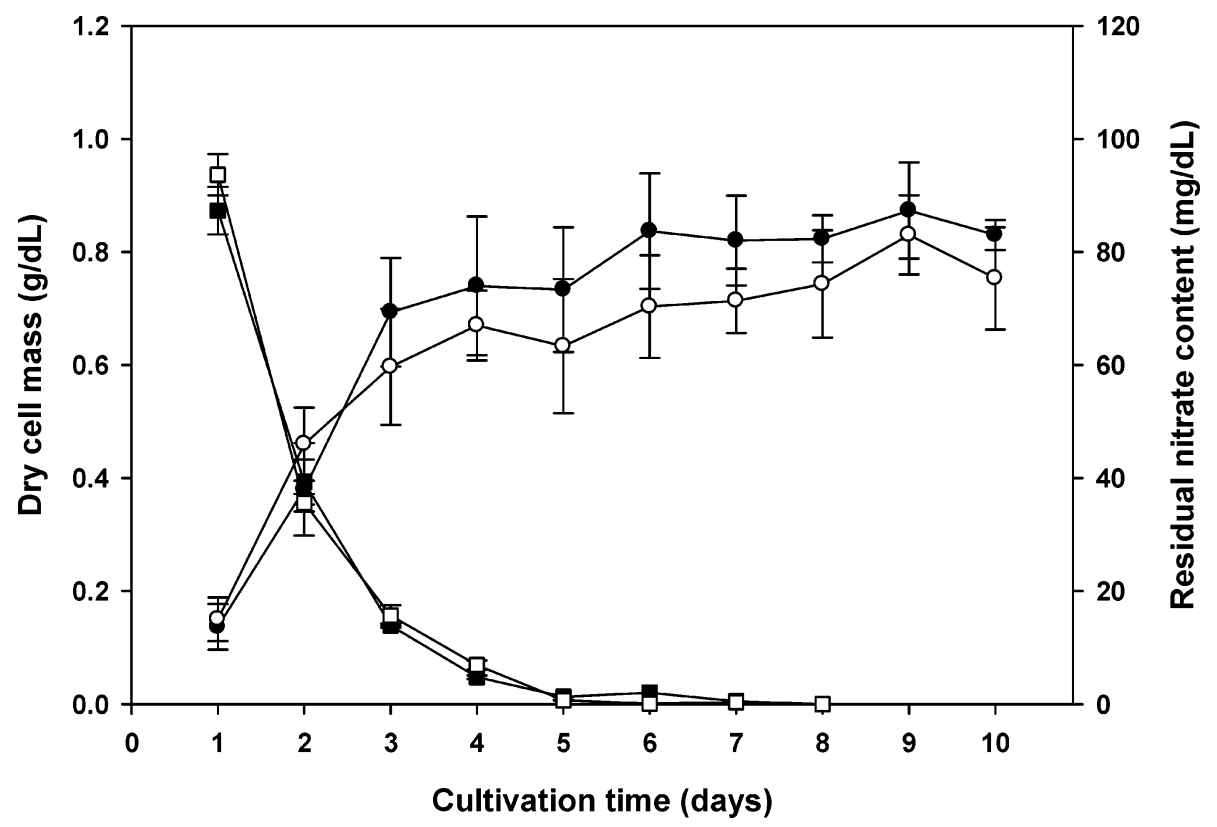

Figure 2. Culture development of M. pilosus BCRC 31527 on the third day of $\mathrm{CHX}$ treatment in batch type of submerged fermentation on a rotary shaker at $32{ }^{\circ} \mathrm{C}$ and $150 \mathrm{rpm}$ for 10 days: dry cell mass of the control $(\mathbf{O})$, dry cell mass on the third day of $\mathrm{CHX}$ treatment $(\mathrm{O})$, residual nitrate content in the control $(\boldsymbol{\square})$, and residual nitrate content on the third day of $\mathrm{CHX}$ treatment $(\square)$. Results are presented as means \pm standard deviations for three independent analyses. All differences at each day were statistically nonsignificant (Student's $t$ test; $P>0.05$ ).

at concentrations lower than $0.5 \mu \mathrm{g} / \mathrm{mL}$; however, some strains of $S$. cerevisiae that are resistant to this drug at $10-50 \mu \mathrm{g} / \mathrm{mL}$ concentrations have been isolated (16). It was found that there were different structures and functions between $\mathrm{CHX}$-sensitive and CHX-resistant ribosomes in eukaryotes. The objective of this work was to apply the minimum inhibitory concentration of $\mathrm{CHX}$ with an appropriate cultivation time to affect MBN production gene expression, but in contrast, under these conditions, the protein syntheses of cell mass growth are not completely inhibited. In the preliminary experiment, $\mathrm{CHX}$ at concentrations of $0.5,1,5,10$, and $50 \mu \mathrm{g} / \mathrm{mL}$ were applied to Monascus cultures by addition at the first and third days during cultivation to evaluate the $\mathrm{CHX}$ level for inhibitory effects on the $\mathrm{MBN}$ production. After that, $\mathrm{CHX}$ at $10 \mu \mathrm{g} / \mathrm{mL}$ in the third day addition of CHX treatment induced an obviously different expression profile of proteins involved in MBN production and cell growth after 10 days of cultivation (data not shown). Then, with $\mathrm{CHX}$ set at $10 \mu \mathrm{g} / \mathrm{mL}$, the $\mathrm{CHX}$ addition time was varied at the first, second, third, fourth, and fifth days during cultivation; the progression time of the cell growth phases influenced the effects of $\mathrm{CHX}$ inhibition on MBN biosynthesis, and cell growth was evaluated. Regarding the substrate medium used, we used a defined medium, glucose nitrate medium, instead of a complex rice substrate, to prevent interference with the $\mathrm{CHX}$ concentration added. Besides, glucose nitrate medium also was considered as a better growth substrate for induction of high pigment productivity in Monascus in previous studies (12).

The inhibitory effects on MBN production by $\mathrm{CHX}$ treatment related to time-dependent response are presented in Figure 1. The inhibition in a time-dependent course revealed two different groups of expression patterns. On the first and fifth days, $\mathrm{CHX}$ treated cells exhibited $\mathrm{CHX}$ resistance in the MBN biosynthesis, showing no or little inhibitory effect on MBN production. Another group, the CHX-treated cells of the second day to the fourth day of treatment, was CHX-sensitive, and the MBN production was significantly inhibited (Figure 1). Interestingly, in the third day of CHX treatment, the changes of the cell growth mass and the nitrate uptake (the inverse of the residual nitrate content in the growth substrate) had a similar tendency during cultivation in both the $\mathrm{CHX}$-treated and the control cells, showing that the Monascus-cultivated cells expressed $\mathrm{CHX}$ resistance in the cell growth mass and nitrate intake during the log phase (Figure 2). Because the changes in cell growth mass and nitrate uptake of the other 4 days of $\mathrm{CHX}$ treatment had similar results as the third day of treatment, the data were not included. In Figure 2, we found that the culture growth of Monascus, after 1 day of log phase, increased sharply up until the third day before stationary phase began; simultaneously, the increase of the nitrate consumption amount was coupled with the increase in the culture growth. Comparing the results of Figures $\mathbf{1}$ and $\mathbf{2}$ together, we observed that $\mathrm{CHX}$ sensitivity in the inhibition of MBN production mainly emerged in $M$. pilosus BCRC 31527 during log phase. Additionally, observed through a phase contrast light microscope (Olympus, BX 41, Tokyo, Japan) at the sixth day of cultivation, the morphologic features of Monascus filaments among the five CHX-treated and the control samples were not obviously different (data not shown).

Intracellular and Mitochondrial Protein Identification. To evaluate the proteome changes that occurred during $\mathrm{CHX}$ sensitive induction at log phase in M. pilosus BCRC 31527 cultivation, we examined the 2-DE PAGE maps of the culture at the third day of CHX treatment. Because the sixth day of cultivated culture exhibited an apparently $\mathrm{CHX}$-inducing difference in MBN production between the CHX-treated and the control cells (Figure 1), it was at this point that we harvested and extracted proteins for 2-DE gel analysis. 2-DE gel analysis is a multistep technique strongly dependent on several factors, such as sample application, quality of gels for the second dimension, and staining duration. Undesirable in vitro proteolysis phenomena were evaluated carefully and excluded totally by blocking Monascus proteases with a high concentration of inhibitor during cell lysis. Preliminary analysis of proteins using IPG strips in the $\mathrm{pH}$ range from 3 to 10 and from 4 to 7 demonstrated that most of the proteins were separated (i.e., 90\%) into the $\mathrm{pH} 3$ and 10 range. Proteins of interest were resolved by $2-\mathrm{DE}$ PAGE in this $\mathrm{pH}$ range and visualized following Sypro 
A

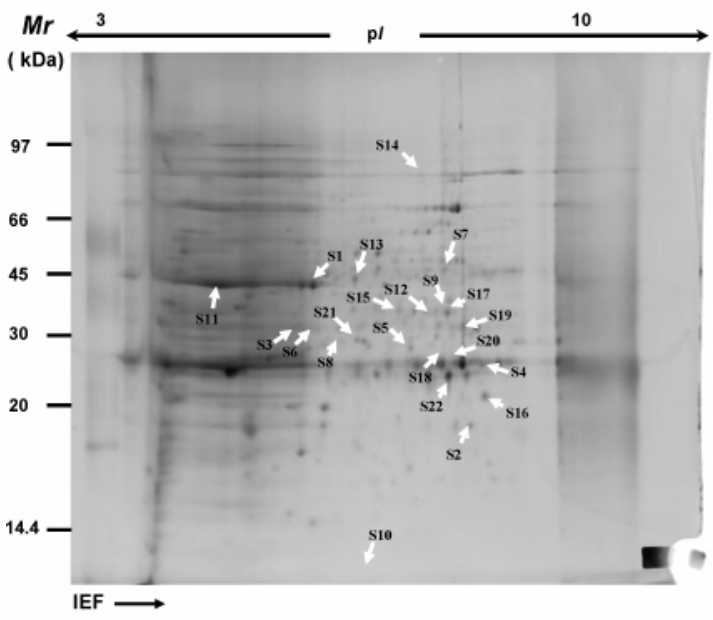

Untreated

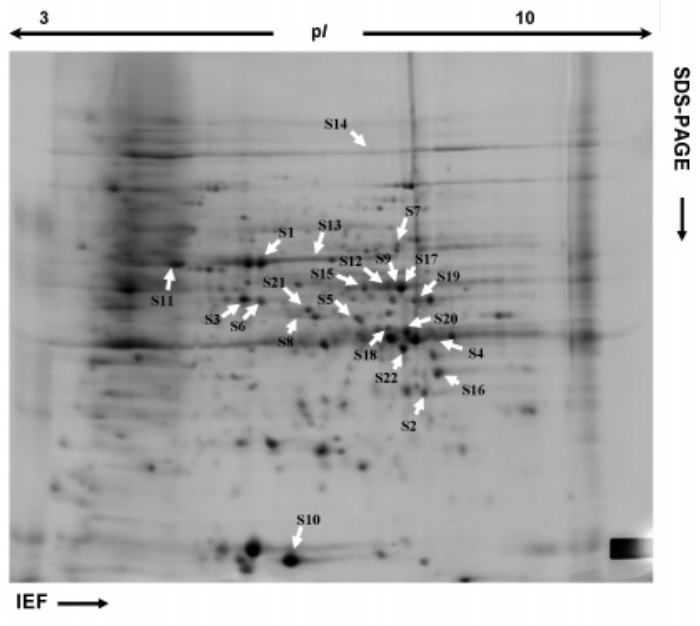

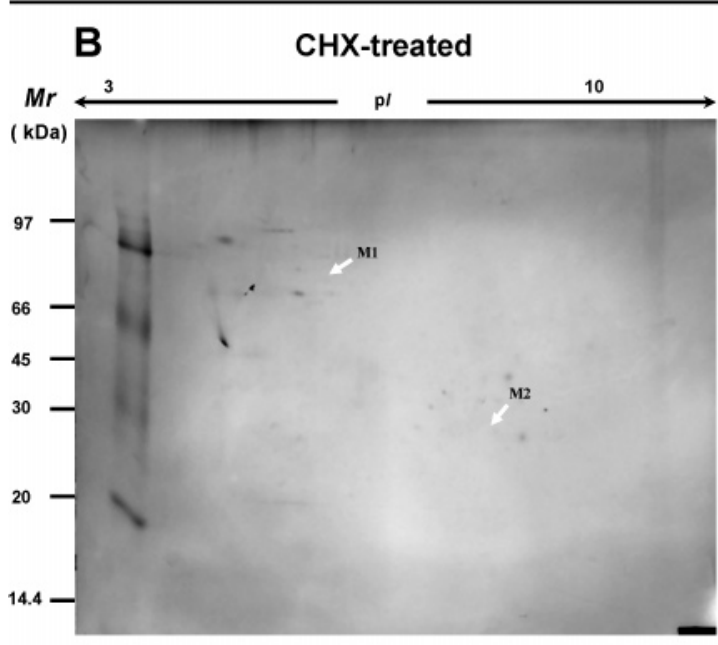

IEF $\longrightarrow$

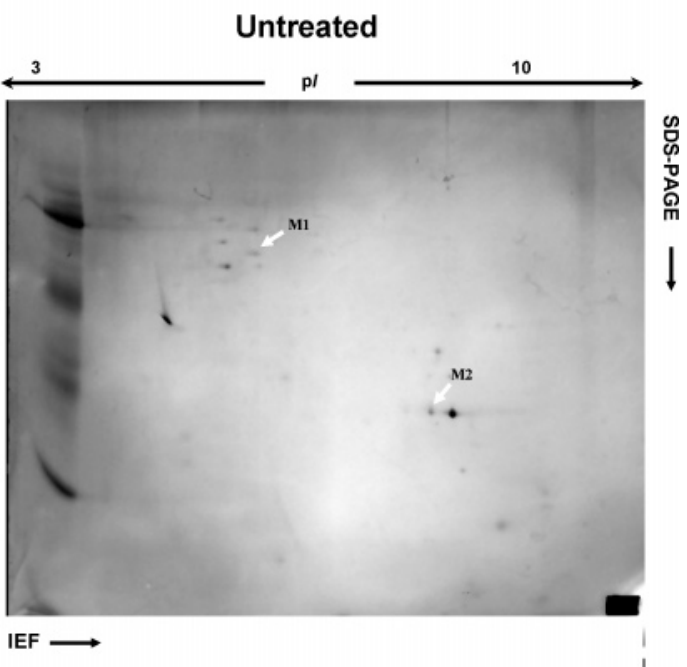

Figure 3. Comparative 2-DE gel analyses of intracellular (A) and mitochondrial (B) proteins of M. pilosus BCRC 31527 between the third day of CHX treatment and the untreated control in submerged fermentation at $32^{\circ} \mathrm{C}$ and $150 \mathrm{rpm}$ at the sixth day of cultivation. The intracellular protein $(300 \mu \mathrm{g} / 350$ $\mu \mathrm{L}$ ) and mitochondrial protein $(250 \mu \mathrm{g} / 350 \mu \mathrm{L})$ extracts of $M$. pilosus BCRC 31527 , respectively, were displayed across a nonlinear IPG strip (pH 3-10, $13 \mathrm{~cm}$ ) in the first dimension and a 10\% SDS-PAGE in the second dimension, stained with Sypro Ruby. The isoelectric point (p/) and molecular mass $\left(M_{\mathrm{r}}\right)$ were marked on horizontal and vertical axes, respectively. Protein spots marked on the maps with arrows and numbers represent 24 identified proteins analyzed with the PDQuest program after $\mathrm{CHX}$ treatment. Details of the proteins are given in Table 1.

Ruby staining (Figure 3). Ensuring that identical proteins in different gels are recognized as being identical in the image registration is the most arduous problem in 2-DE gel analysis. With registration of several gel images, a single reference or consensus gel image combining the information content of all individual images was generated. Here, this reference gel consisted of a representative set of spots generated from four repeated registered gel images of the control or the CHX-treated cells and was used to compare each sample. The 2-DE protein spot patterns obtained from four separate gels from the control and the CHX-treated cells, respectively, were easily reproduced in terms of both the total number of protein spots and their relative positions and intensities from the cells and mitochondria (Figure 3).

Some 75 spots from the intracellular and mitochondrial 2-DE gels were cut, and MALDI-TOF/TOF MS was initially used to identify the spots. In case of difficulty in identification by MS in some spots, MALDI-TOF/TOF MS/MS combined with LCMS with similar derivatization was used. From the 75 protein spots cut for MALDI-TOF/TOF analysis, 24 proteins were identified, giving a $32 \%$ identification rate. In a search of the protein database, 21 proteins for which a positive identification could be made using peptide mass fingerprinting (PMF) with cross-species identification (CSI) alone (17) were confirmed using MALDI-TOF/TOF MS. By CSI, these identified proteins were matched to known proteins from related species of filamentous fungi, such as A. niger, and to less closely related bacterium species, such as Bacillus subtilis. Identified proteins are highlighted and numbered on the protein reference map shown in Figure 3. The types of proteins identified included highly conserved aminoacyl-tRNA synthetases (aaRSs) in cells and mitochondria (18), hydrolylases, isomerases, lyases, transcriptional regulators, and GTP-binding proteins. Two of these identified protein spots, matching subunits of known proteins, were DNA-directed RNA polymerase $\omega$ chain (RNAP $\omega$ ) and FO synthase subunit 21 (FO). For the protein spots in the gels that could not be identified by MALDI mass mapping, MS/MS and/or LC-MS were used for a more accurate analysis of the ambiguous protein spots. One protein spot matched to a known $M$. purpureus protein, and another two protein spots matched to known proteins from $S$. cerevisiae and Hypocrea jecorina. These were glyceraldehyde-3-phosphate dehydrogenase (GAP$\mathrm{DH})$, ribose-phosphate pyrophosphokinase 3 (PRPP), and phosphoglycerate kinase (PGK), respectively. 
Table 1. List of Identified Protein Spots of 2-DE Gel Analyses of Intracellular and Mitochondrial Proteins of M. pilosus BCRC 31527 between the Third Day of CHX Treatment and the Untreated Control

\begin{tabular}{|c|c|c|c|c|c|c|c|c|c|}
\hline $\begin{array}{l}\text { spot } \\
\text { name }\end{array}$ & $\begin{array}{l}\text { protein } \\
\text { identified } \\
\left(M_{\mathrm{r}} / \mathrm{pl}\right)^{\mathrm{a}}\end{array}$ & sources & $\begin{array}{c}\text { sequence } \\
\text { coverage } \\
(\%)\end{array}$ & $\begin{array}{c}\text { accession } \\
\text { no. }{ }^{b}\end{array}$ & $\begin{array}{l}\text { MOWSE } \\
\text { score }\end{array}$ & $\begin{array}{c}\text { fold } \\
\text { change }\end{array}$ & $\begin{array}{l}\text { type of } \\
\text { analysis }\end{array}$ & database & $\begin{array}{c}\text { peptide } \\
\text { sequence }\end{array}$ \\
\hline S1 & ValRS (103 kDa/6.98) & $\begin{array}{l}\text { Mycoplasma mycoides } \\
\text { ssp. mycoides SC }\end{array}$ & 19 & SYV_MYCMS & 57 & -2.4 & PMF & SwissProt & MSKSLGNGIDPMDVINNNGCDSLR \\
\hline S2 & TyrRS (46 kDa/4.69) & Salinibacter ruber & 22 & SYY_SALRD & 42 & -6.5 & PMF & SwissProt & AVLIVGDFTGMIGDPSGR \\
\hline S3 & Pep B (47 kDa/5.37) & Pectobacterium atrosepticum & 24 & PEPB_ERWCT & 64 & -1.9 & PMF & SwissProt & SDMGGAATLTGALALAASRGLQQR \\
\hline S4 & OTC (38 kDa/6.73) & Pachysolen tannophilus & 25 & OTC_PACTA & 46 & -16.7 & PMF & SwissProt & MINSISNTVLLKSVVSK \\
\hline S5 & $\operatorname{SIR}(65 \mathrm{kDa} / 6.44)$ & Vibrio fischeri & 20 & CYSI_VIBF1 & 35 & -2.9 & PMF & SwissProt & VHQGDFRMTANQNLIVAGVPSEQK \\
\hline S6 & $\mathrm{NAG}(27 \mathrm{kDa} / 5.60)$ & B. subtilis & 24 & NAGB_BACSU & 35 & -3.0 & PMF & SwissProt & KVMECQTYEELSQIAAR \\
\hline S7 & $\operatorname{ACCD}(37 \mathrm{kDa} / 5.64)$ & Williopsis saturnus & 31 & 1A1D_WILSA & 49 & -1.9 & PMF & SwissProt & IVVCCVTGSTTAGILAGMAQYGR \\
\hline S8 & $\begin{array}{l}\text { RNAP } \omega \text { (EC 2.7.7.6) } \\
\quad(11 \mathrm{kDa} / 5.50)\end{array}$ & Thermus aquaticus & 36 & RPOZ_THEAQ & 41 & -2.9 & PMF & SwissProt & TLEGLYDDPNAVTWAMKELLTGR \\
\hline S9 & $\operatorname{NanR}(30$ kDa/6.01) & E. coli 06 & 26 & NANR_ECOL6 & 45 & -8.9 & PMF & SwissProt & ARVSRPSADTIIGELSGMAK \\
\hline S10 & GreA (18 kDa/5.99) & Mycoplasma genitalium & 36 & GREA_MYCGE & 42 & -2.2 & PMF & SwissProt & VSLGSTVEIYDYSSK \\
\hline S11 & SarA (21 kDa/5.78) & A. niger & 23 & SAR1_ASPNG & 19 & 2.0 & PMF & SwissProt & VPLEGIRPIEVFMCSVVMR \\
\hline S12 & LepA (66 kDa/5.64) & $\begin{array}{l}\text { Xanthomonas campestris } \\
\text { pv. campestris }\end{array}$ & 22 & LEPA_XANC8 & 52 & -30.9 & PMF & SwissProt & TDGTIIPMDNPSKLPPLNHVEEIR \\
\hline S13 & $\begin{array}{l}\text { FO (EC 2.5.1) } \\
\quad(44 \mathrm{kDa} / 5.93)\end{array}$ & Methanococcus maripaludis & 35 & COFH1_METMP & 45 & 2.0 & PMF & SwissProt & LGTKLSQISLNCGANDIGGTLMEESISK \\
\hline S14 & $\begin{array}{l}\text { PRPP (EC 2.7.6.1) } \\
\quad(35 \mathrm{kDa} / 8.51)\end{array}$ & S. cerevisiae & 21 & KPR3_YEAST & 30 & -5.4 & PMF & SwissProt & ENVNYMDSIIISPDAGGAKR \\
\hline S15 & GlcE (35 kDa/7.72) & $\begin{array}{l}\text { Candidatus Kuenenia } \\
\text { stuttgartiensis }\end{array}$ & 28 & gi|91204592 & 64 & 1.0 & PMF & NCBI & KSVEMPAYDANINILGSLNLCQLSMK \\
\hline S16 & PCD (12 kDa/5.4) & Sinorhizobium meliloti & 77 & PHS_RHIME & 49 & -2.7 & PMF & SwissProt & VDVTLSTHDADGLTELDFK \\
\hline S17 & GAPDH (36 kDa/6.33) & Monascus purpureus & 18 & G3P_MONAN & 235 & -3.5 & LC-MS & SwissProt & VPTSNVSVVDLTARLEK \\
\hline S18 & PEPC (98 kDa/5.44) & Photobacterium profundum & 19 & CAPP_PHOPR & 47 & 1.3 & PMF & SwissProt & WGFAVVENSLWHAVPEFLRQFDEK \\
\hline S19 & PGM (26 kDa/7.44) & S. cerevisiae & 26 & YO283̄_YEAST & 46 & -3.9 & PMF & SwissProt & VGNTQHLGDGEFVVSDLR \\
\hline S20 & PGK (44 kDa/6.16) & H. jecorina & 4 & PGK_TRIRE & 105 & -6.6 & LC-MS & SwissProt & LSITDVDLK \\
\hline S21 & $\mathrm{BE}(76 \mathrm{kDa} / 5.62)$ & $\begin{array}{l}\text { Bacillus thuringiensis } \\
\text { serovar konkukian }\end{array}$ & 23 & GLGB_BACHK & 59 & 1.4 & PMF & SwissProt & YYESYNIFGAHIVTEDEMR \\
\hline S22 & $\operatorname{Ros} A r(16 \mathrm{kDa} / 6.58)$ & Agrobacterium tumefaciens & 38 & ROSA_AGRRD & 48 & 2.5 & PMF & SwissProt & WDLQVDYPMVAPAYAEARSR \\
\hline M1 & ThrRS $(73 \mathrm{kDa} / 5.31)^{e}$ & Oceanobacter sp. RED65 & 25 & Q1N5Z̄7_9GAMM & 67 & -69.3 & PMF & MSDB & ATIAGEVDGQLIDACDKIEHDAQLR \\
\hline M2 & AspRS $(66 \mathrm{kDa} / 5.48)^{e}$ & Streptococcus mutans & 21 & SYD1_STRMU & 60 & -22.9 & PMF & SwissProt & QLVMDFGVAGFATATIEKGQVTGSLK \\
\hline
\end{tabular}

\footnotetext{
${ }^{a}$ Theoretical molecular mass $\left(M_{\mathrm{r}}\right)$ of the matched protein and theoretical $\mathrm{p} /$ of the matched protein in database. ${ }^{b}$ SwissProt, NCBI, or MSDB accession number. ${ }^{c}$ The fold change of protein content in each protein spot is to compare each $\mathrm{CHX}$-treated value with the control to show the deregulation. ${ }^{d}$ Proteins identified by using MALDITOF/TOF MS through PMF or LC-MS. ${ }^{e}$ Located in the mitochondria.
}

Proteome Response to CHX Treatment. To understand the regulated expressions of these identified proteins in response to $\mathrm{CHX}$ treatment in the cultivated M. pilosus BCRC 31527, a comparison of the identified protein contents between the CHXtreated and the control cells was depicted as "fold change" in Table 1 by four independent 2-DE gels and PDQuest programaided analysis. The fold change of protein content in each protein spot was demonstrated by comparison of the $\mathrm{CHX}$-treated with the control to reveal the deregulation of the protein spot. Of the 24 protein spots identified, 18 were down-regulated in the CHX-treated cells. These included several aaRSs in cells and mitochondria, metabolic enzymes [such as peptidase B (Pep B), 1-aminocyclopropane-1-carboxylate deaminase (ACCD), and PRPP], and several glycolytic enzymes [GAPDH, phosphoglycerate mutase YOR283W (PGM), and PGK]. Only six identified proteins, including RosAr, GTP-binding protein sarA (SarA), FO, UDP-glucose 4-epimerase (GlcE), phosphoenolpyruvate carboxylase (PEPC), and 1,4- $\alpha$-glucan branching enzyme $(\mathrm{BE})$, revealed up-regulation or remained constant as compared to the control cells.

\section{DISCUSSION}

Proteomics, which aims at characterizing the entire protein complement expressed in cells, provides complementary information and direct evidence to unravel the unknown response to changes in growth stress. Here, the resulting data indicated that the cultivated Monascus exhibited a $\mathrm{CHX}$ resistance for programming growth mass under CHX treatment (Figure 2). By comparison, interestingly, the log-phase Monascus cells revealed $\mathrm{CHX}$ sensitivity and showed inhibition in MBN biosynthesis under CHX addition (Figure 1). When this difference of $\mathrm{CHX}$ sensitivity in the metabolic inhibition on MBN biosynthesis is clarified, it will provide a clue for understanding the metabolic regulation of secondary metabolite MBN production in Monascus. We used 2-DE-based proteomics to examine the protein profiles in the third day of $\mathrm{CHX}$ treatment, trying to elucidate the metabolic regulation induced by the CHX-induced inhibition on MBN production. A total of 24 identified proteins were uncovered in this work, among which 18 were down-regulated and five were up-regulated under $\mathrm{CHX}$ treatment (Table 1). One protein remained constant, showing CHX insensitivity.

A group of amino acid formation-related enzymes, including mitochondrial precursor ornithine carbamoyltransferase (OTC), sulfite reductase [NADPH] hemoprotein $\beta$-compone (SIR), ACCD, and putative pterin- $4-\alpha$-carbinolamine dehydratase (PCD), revealed co-down-regulation in the CHX-treated cells. The OTCs are a family of enzymes that catalyze the production of citrulline from carbamoyl-phosphate and ornithine $(19,20)$. This reaction is part of the arginine biosynthetic pathway, and in some organisms, the reaction is also part of the arginine deaminase pathway (20). Arginine metabolism is also linked to the pyrimidine biosynthetic pathway through carbamoyl phosphate in vivo in S. cerevisiae (19). Another down-regulated expression protein, SIR, was also associated with biosynthesis of amino acids (21). In $S$. cerevisiae, SIR is involved in the assimilatory reduction of sulfate to sulfide, which is essential for the biosynthesis of the sulfur-containing amino acids (such as methionine and cysteine) and an important metabolic intermediate $S$-adenosylmethionine (SAM) $(21,22)$. In $S$. 
cerevisiae, the sulfur amino acid pathway and the SAM pathway are both involved in transcriptional regulation (22). ACCD is a pyridoxal-phosphate-dependent enzyme that degrades aminocyclopropane-1-carboxylate (ACC) to $\alpha$-ketoglutarate (the precursor of the amino acids valine and threonine) (23). Previously found in bacteria, yeast, and fungi, ACC is formed from SAM via a ring-closing $\gamma$-displacement reaction (24). Here, the codown-regulated expression of ACCD and SIR suggested a decrease in valine and threonine pools, which, in turn, affects valine- and threonine-related protein synthesis. The fact that SAM is at the downstream pathways of SIR as well as the codown-regulated expression of OTC precursor, SIR, and ACCD together suggests that SAM would be expressed in downregulation. SAM serves as a methyl donor for many methylation reactions, including transmethylation in polyketide biosynthesis (21). The suggestion of down-regulation in SAM in the CHXtreated sample may lead to repression of polyketide formation. In addition, PCD is involved in catalyzing the dehydration step in the cyclic regeneration of tetrahydrobiopterin (BH4) (25), an essential cofactor required for the aromatic amino acid hydroxylation pathway, such as phenylalanine and tyrosine in Schizosaccharomyces pombe and Pseudomonas aeruginosa (26). The PCD downshift might lead to a decrease in aromatic amino acid pools in the CHX-treated cells. The dimeric form of PCD is also a transcriptional activator functioning as a dimerization cofactor (27).

In parallel, four conserved aaRSs, including intracellular valyl-tRNA synthetase (ValRS) and tyrosyl-tRNA synthetase (TyrRS) and mitochondrial aspartyl-tRNA synthetase 1 (AspRS) and threonyl-tRNA synthetase (ThrRS), were taken together in down-regulated expression with those amino acid formationrelated enzymes in the $\mathrm{CHX}$-treated cells. AaRSs play a critical role in protein synthesis, because they are responsible for accurate charging of a given set of tRNAs with their cognate amino acids (28). In addition to the primary role in protein synthesis, it has often been suggested that these enzymes also play important regulatory roles in cells (29). For example, various aaRSs have been reported to be implicated, at least indirectly, in the regulation of certain amino acid biosynthetic pathways (30). In Escherichia coli, the expression of the gene thrRS encoding ThrRS is under the control of two different regulatory loops: translational feedback regulation and growth rate-dependent control (31). According to a previous study, ThrRS is transiently derepressed during starvation for threonine in E. coli (32). Additionally, AspRS expression in yeast was also regulated by a feedback mechanism (33). As stated above, the effects of CHX treatment on the co-down-regulation of amino acid formation-related enzymes, OTC precursor, SIR, ACCD, and PCD taken together, may lead to starvation in amino acid and related intermediate pools, at least in arginine, sulfurcontaining amino acids, and aromatic amino acids, such as phenylalanine and tyrosine. Interestingly, in the resulting data, there was a similar tendency of the changes in the cell growth mass and nitrate uptake between the treated and the control samples (Figure 2). In contrast, the four aaRSs were together down-regulated in the $\mathrm{CHX}$-treated sample. Inorganic nitrate serves as an excellent nitrogen source for many fungal species. In fungi, utilization of nitrate requires the de novo synthesis of nitrate reductase, which is induced specifically by nitrate. However, in wild-type Chlamydomonas reinhardtii cells, nitrate reductase expression is not repressed by $\mathrm{CHX}$ treatment in the presence of nitrate in the media (34). On the basis of the aaRSs as a translational regulation role, it was suggested that the observed coordinated down-regulation of the aaRSs with these associated enzymes in the CHX-treated cells may reflect the cultivated cell effort, acting through feedback mechanism, in maintaining cellular metabolism homeostasis under the action of translational inhibitor $\mathrm{CHX}$ on ribosomes in the log-phase cells.

Furthermore, several glycolytic enzymes, including GAPDH, PGM, and PGK, were down-regulated in the CHX-treated cells. On the other hand, simultaneously, a group of glycolysis branch enzymes, including BE, PEPC, and FO, revealed an opposite correlation with those above glycolytic enzymes in an upregulated expression in the $\mathrm{CHX}$-treated cells. In glycolysis, PGK is the first cytoplasmic ATP-producing enzyme, catalyzing the reversible transfer of phosphate between 1,3-bisphosphoglycerate and $\operatorname{ADP}(35,36)$. Moreover, PGM, regarded as a glycolytic housekeeping enzyme, catalyzes the interconversion of 3-phosphoglyceric acid (3-PGA) and 2-phosphoglyceric acid (2-PGA) in glycolysis (37). In glycolysis, the conversion of 3-PGA to 2-PGA allows for the eventual synthesis of ATP by means of enolase and pyruvate kinase (38). However, in the literature, the precursors for polyketide formation arise from the condensation of an acety-CoA molecule with malony-CoA molecules. The decrease of glycolytic flux subsequently, in turn, led to a reduction in the formation of polyketide precursors (including MBN), through suppressing the flux of the intermediate acety-CoA molecule. The resultant down-regulation in GAPDH, PGK, and PGM together suggested the reduction in the glycolytic flux, which, in turn, lead to a reduction in the ATP generation that was needed to maintain cellular homeostasis in the CHX-treated cells.

Another interesting observation was the co-down-regulation of the six metabolic regulation proteins: $\mathrm{RNAP} \omega$, transcription elongation factor greA (GreA), GTP-binding protein lepA (LepA), PRPP, NanR, and Pep B. Transcription, the DNAdirected synthesis of RNA, is the first step in the cascade of events that leads to gene expression. The central role of RNAP in transcription is to synthesize the nascent RNA chain with high fidelity and at a reasonable rate (39). Transcription elongation is highly regulated both by protein factors that bind to the DNA template, the RNA transcript, or the transcription complex as it moves along the template and by specific sequence elements (expressed either by DNA or RNA) that interact with the transcribing polymerase at each template position (40). As a result of these properties, RNAP appears to evolve in such a way that it catalyzes multiple reactions and displays an unprecedented level of dynamic flexibility. Thus, accessory proteins, such as GreA (to promote transcription elongation) and GreB, as well as others, appear to recognize and/or act on these different conformations and also modulate the distribution between states in bacteria (41). Additionally, LepA (a highly conserved GTPase in molecular switches with diverse functions) was reported to group with the elongation factors (GreA and $\mathrm{GreB}$ ) in regulating ribosome function (42). Bacterial GreA and GreB promote transcription elongation by stimulating an endogenous, endonucleolytic cleavage activity of the RNA polymerase (42). For many genes, transcription requires the assembly of a large nucleoprotein complex, including general transcription factors. In the CHX-treated sample, the down-regulated expression of RNAP $\omega$ with these two accessory proteins, GreA and LepA, indicated that the decrease in transcription resulted from coupling transcription and translation.

Here, PPRP also was down-regulated as the cultivated cells responded to the $\mathrm{CHX}$ inhibition in the peptidyl elongation reaction on the ribosome. PPRP, catalyzing the transfer of an intact diphosphate (PP) group from ATP to ribose-5-phosphate 
and resulting in the formation of AMP and 5-phospho-D-ribosyl 1-diphosphate (43), has a central role in cellular biochemistry in linking carbon and nitrogen metabolism and is required for the de novo and salvage synthesis of purine, pyrimidine, and pyridine nucleotides (44). Most PRPPs are regulated in an allosteric manner, in which ADP generally acts as the most potent inhibitor (45). As previously stated, ATP generation decreased as the glycolytic flux decreased in the CHX-treated cells. Moreover, PPRP, which provides nucleotides, is at the upstream steps of RNAP-related pathways. Therefore, on the basis of the down-regulation of ATP energy generation and RNAP-related pathway flux, it was presumably possible that the co-down-regulation of PRPP, NanR, and Pep B was due to the action of feedback regulation between transcription and translation. The trigger of the regulation between transcription and translation level might reflect the cellular energy homeostasis status in response to $\mathrm{CHX}$ treatment. Because the decrease of PRPP in the expression may result in an inability to provide enough nucleotide pools for downstream transcription biosynthesis, consequently, it may be reasoned that the enzymes involved in subsequent transcriptional regulation, NanR (which belongs to the transcriptional regulator FadR/GntR family) (46, 47) and Pep B (a membrane-associated enzyme involved in transcriptional regulation in the processing of intracellular proteins implicated in DNA binding) $(48,49)$, were coordinated together in down-regulation in the CHX-treated cells.

By comparison, as stated above, we observed that the CHX triggered the up-regulation in PEPC, FO, and $\mathrm{BE}$, which are implicated in the switch of glycolysis, gluconeogenesis, or/and energy generation. In $S$. cerevisiae, it was reported that glycogen metabolism is regulated at the transcription level (50). The degree of glycogen branching is thought to be governed by the balance between glycogen synthesis and branching activities involved in BE allosteric regulation during metabolic transitions such as starvation, diauxic growth lags, or approach to stationary phase in S. cerevisiae (51). Similar to BE, another allosteric enzyme PEPC (acetyl-CoA is a powerful allosteric activator of PEPC in many species of organisms) (52) branches from glycolysis through a carboxylation reaction to replenish intermediate pools (such as acetyl-CoA) to the tricarboxylic acid cycle in response to limited intermediate supply (53). In addition, interestingly, CHX also induced an up-regulated expression in RosAr and SarA. Vienken et al. found that in A. nidulans, the negative transcriptional regulator RosAr was usually very low in transcription level and was only transiently up-regulated upon carbon starvation in mycelium, inducing metabolic enzymes for the mobilization of reserved material to adapt to the starving situation (54). Candida maltosa was also reported to have the ability to regulate gene expression as a $\mathrm{CHX}$-resistant ribosome in response to a high level of CHX treatment (16). Moreover, SarA was reported to play an important functional role downstream of Rab 5 (a member of the small GTPase family), which is implicated in regulating transport between specific organelles (51). The observations of reverse deregulation expression between these glycolytic enzymes and glycolytic pathway switch enzymes suggested that the CHX-treated cells were attempting to maintain metabolic energy homeostasis under energy starvation status by allosteric regulation in the glycolytic pathway.

In contrast, GlcE expression remained constant under the CHX treatment. GlcE is a highly conserved enzyme that catalyzes the interconversion of UDP-galactose and UDPglucose, playing the pivotal role in cellular assembly of complex polysaccharides and other glycosylated macromolecules (55). In a previous study, the expression of $\mathrm{CHX}$ insensitivity in $\mathrm{GlcE}$ under catabolite repression was reported in $S$. cerevisiae (56). Therefore, the maintenance of GlcE in a constant expression that may reflect the growth mass of the CHX-treated cells was not significantly different with the control during fermentation (Figure 2).

In the literature, CHX-resistant expression is a taxonomic marker in yeasts. In S. cerevisiae, $\mathrm{CHX}$ treatment, which inhibits protein synthesis, may cause metabolic stress and stimulate stress response pathways, inducing different expression between $\mathrm{CHX}$ sensitivity and CHX resistance in ribosome function (57). In C. maltosa, there is a gene (designated RIM-C for ribosome modification by $\mathrm{CHX}$ ) that functions in the presence of $\mathrm{CHX}$ to modify ribosomes so that certain protein synthesis in the cells is no longer inhibited by $\mathrm{CHX}$ (57). In this work, the resulting data indicated that, under $\mathrm{CHX}$ treatment, the cultivated Monascus cells exhibited a CHX resistance for programming growth mass (Figure 2); in comparison, the log-phase Monascus cells revealed CHX sensitivity and inhibited in MBN biosynthesis (Figure 1). Under proteome response, the CHX-treated induced proteins were involved in glycolysis, gluconeogenesis, peptide biosynthesis, and transcriptional and translational regulation. The deregulation of certain proteins identified in this work may provide a clue to identify the metabolic pathways concerning fermentation processes in this industrial fungus.

Taken together, our proteomic comparison of M. pilosus BCRC 31527 between the CHX-treated and the untreated cells revealed that $\mathrm{CHX}$ treatment induced an altered expression pattern in the intracellular and mitochondrial proteins in Monascus. The different expression in the MBN production between the CHX-treated and the untreated cells presumably reflected the altered expression of the identified proteins. The deregulation of the proteins suggested an adaptive response of the fungus to cope with the sudden protein translational inhibitor treatment, including an immediate arrest at the onset of MBN production. We indicated a link between the Monascus cultivated cell effort in maintaining cellular metabolism homeostasis and an immediate arrest at the onset of MBN formation under the action of the translational inhibitor CHX. The suggestion that the up-regulation of several glycolysis switch enzymes between gluconeogenesis and glycolysis, caused by $\mathrm{CHX}$ addition, may be beneficial for low-glycolytic flux tolerance needs to be further corroborated. In addition, that the MBN biosynthesis was blocked by $\mathrm{CHX}$ treatment at the third day, during the log phase, indicated that, in M. pilosus BCRC 31527 , the MBN production was programmed to rely on the stored RNA and new synthesis of proteins, not stored proteins in cells. However, secondary polyketide biosynthesis is involved in using acetyl-CoA as the building block and subsequently multiple transformation steps, including reduction, oxidative rearrangement, methylation, and ring modification, yielding several stable intermediate precursors to form polyketides. Here, the depression of several metabolic enzymes, including glycolytic enzymes (providing acetyl-CoA building block), SAM-associated enzymes (methylation, lovastatin methyl group derived from SAM), GTP-binding proteins, and transcriptional regulators, and the up-regulation of allosteric enzymes (such as PEPC), were coupled together with the blocking of MBN production under $\mathrm{CHX}$ treatment. The diverse correlation of the identified proteins expression indicated that the MBN biosynthesis was implicated in modulating the expression of multiple proteins. 


\section{ABBREVIATIONS USED}

aaRSs, aminoacyl-tRNA synthetases; ACC, aminocyclopropane-1-carboxylate; ACCD, 1-aminocyclopropane-1-carboxylate deaminase; ACN, acetonitrile; AspRS, aspartyl-tRNA synthetase 1; BE, 1,4- $\alpha$-glucan branching enzyme; CHAPS, 3-[(3-cholamidopropyl) dimethylammonio]-1-propane sulfonate; CHCA, $\alpha$-cyano-4-hydroxycinnamic acid; CHX, cycloheximide; DTT, dithiothreitol; FO, FO synthase subunit 21; GAPDH, glyceraldehyde-3-phosphate dehydrogenase; GlcE, UDP-glucose 4-epimerase; GreA, transcription elongation factor greA; IAA, iodoacetamide; IPG, immobilized $\mathrm{pH}$ gradients; HEPES-KOH, $N$-(2-hydroxyethyl) piperazine- $N$ '-(2-ethanesulfonic acid) potassium salt; LepA, GTP-binding protein lepA; MBN, monascorubrin; NanR, transcriptional regulator nanR; OTC, ornithine carbamoyltransferase; PCD, putative pterin-4- $\alpha$-carbinolamine dehydratase; Pep B, peptidase B; PEPC, phosphoenolpyruvate carboxylase; PGA, phosphoglyceric acid; PGK, phosphoglycerate kinase; PGM, phosphoglycerate mutase YOR283W; PMSF, phenylmethanesulfonyl fluoride; PRPP, ribose-phosphate pyrophosphokinase 3; RNAP $\omega$, DNA-directed RNA polymerase $\omega$ chain; RosAr, transcriptional regulatory protein rosAr; SarA, GTP-binding protein sarA; SAM, $S$-adenosylmethionine; SDS, sodium dodecyl sulfate; SIR, sulfite reductase [NADPH] hemoprotein $\beta$-component; TFA, trifluoroacetic acid; ThrRS, threonyl-tRNA synthetase; TyrRS, tyrosyl-tRNA synthetase; ValRS, valyl-tRNA synthetase.

\section{ACKNOWLEDGMENT}

We gratefully thank Cheng-Chung Liao, Ph.D., from The Institute of Biochemistry, National Yang Ming University, for technical assistance with MALDI-TOF/TOF LC-MS.

\section{LITERATURE CITED}

(1) Cicero, A. F.; Brancaleoni, M.; Laghi, L.; Donati, F.; Mino, M. Antihyperlipidaemic effect of a Monascus purpureus brand dietary supplement on a large sample of subjects at low risk for cardiovascular disease: a pilot study. Complement Ther. Med. 2005, 13, 273-278.

(2) Lin, W. Y.; Song, C. Y.; Pan, T. M. Proteomic analysis of Caco-2 cells treated with monacolin K. J. Agric. Food Chem. 2006, 54, $6192-6200$

(3) Hajjaj, H.; Klaebe, A.; Loret, M. O.; Tzedakis, T.; Goma, G.; Blanc, P. J. Production and identification of N-glucosylrubropunctamine and $\mathrm{N}$-glucosylmonascorubramine from Monascus ruber and occurrence of electron donor-acceptor complexes in these red pigments. Appl. Environ. Microbiol. 1997, 63, 26712678 .

(4) Liu, B. H.; Wu, T. S.; Su, M. C.; Chung, C. P.; Yu, F. Y. Evaluation of citrinin occurrence and cytotoxicity in Monascus fermentation products. J. Agric. Food Chem. 2005, 53, 170175.

(5) Hajjaj, H.; Klaebe, A.; Loret, M. O.; Goma, G.; Blanc, P. J.; Francois, J. Biosynthetic pathway of citrinin in the filamentous fungus Monascus ruber as revealed by 13C nuclear magnetic resonance. Appl. Environ. Microbiol. 1999, 65, 311-314.

(6) Shimizu, T.; Kinoshita, H.; Ishihara, S.; Sakai, K.; Nagai, S.; Nihira, T. Polyketide synthase gene responsible for citrinin biosynthesis in Monascus purpureus. Appl. Environ. Microbiol. 2005, 71, 3453-3457.

(7) Kennedy, J.; Auclair, K.; Kendrew, S. G.; Park, C.; Vederas, J. C.; Hutchinson, C. R. Modulation of polyketide synthase activity by accessory proteins during lovastatin biosynthesis. Science 1999, 284, 1368-1372.

(8) Fischbach, M. A.; Walsh, C. T. Biochemistry directing biosynthesis. Science 2006, 314, 603-605.
(9) Hofmann, G.; McIntyre, M.; Nielsen, J. Fungal genomics beyond Saccharomyces cerevisiae? Curr. Opin. Biotechnol. 2003, 14, 226-231.

(10) Fujiki, M.; Verner, K. Coupling of protein synthesis and mitochondrial import in a homologous yeast in vitro system. $J$. Biol. Chem. 1991, 266, 6841-6847.

(11) Lin, W. Y.; Ting, Y. C.; Pan, T. M. Proteomic response to intracellular proteins of Monascus pilosus grown under phosphatelimited complex medium with different growth rates and pigment production. J. Agric. Food Chem. 2007, 55, 467-474.

(12) Teng, S. S.; Feldheim, W. Anka and anka pigment production. J. Ind. Microbiol. Biotechnol. 2001, 26, 280-282.

(13) Sastry, K. V.; Moudgal, R. P.; Mohan, J.; Tyagi, J. S.; Rao, G. S. Spectrophotometric determination of serum nitrite and nitrate by copper-cadmium alloy. Anal. Biochem. 2002, 306, 79-82.

(14) Grinyer, J.; McKay, M.; Herbert, B.; Nevalainen, H. Fungal proteomics: Mapping the mitochondrial proteins of a Trichoderma harzianum strain applied for biological control. Curr. Genet. 2004, 45, 170-175.

(15) Weinert, T. A.; Hartwell, L. H. Characterization of RAD9 of Saccharomyces cerevisiae and evidence that its function acts posttranslationally in cell cycle arrest after DNA damage. Mol. Cell. Biol. 1990, 10, 6554-6564.

(16) Kaiwai, S.; Murao, S.; Mochizuki, M.; Shibuya, I.; Yano, K.; Taikagi, M. Drastic alteration of cycloheximide sensitivity by substitution of one amino acid in the L41 ribosomal protein of yeasts. J. Bacteriol. 1992, 174, 254-262.

(17) Wilkins, M. R.; Williams, K. L. Cross-species protein identification using amino acid composition, peptide mass fingerprinting, isoelectric point and molecular mass: a theoretical evaluation. J. Theor. Biol. 1997, 186, 7-15.

(18) Fechter, P.; Rudinger-Thirion, J.; Tukalo, M.; Giege, R. Major tyrosine identity determinants in Methanococcus jannaschii and Saccharomyces cerevisiae tRNA(Tyr) are conserved but expressed differently. Eur. J. Biochem. 2001, 268, 761-767.

(19) Zuniga, M.; Perez, G.; Gonzalez-Candelas, F. Evolution of arginine deiminase (ADI) pathway genes. Mol. Phylogenet. Evol. 2002, 25, 429-444.

(20) Crabeel, M.; Lavalle, R.; Glansdorff, N. Arginine-specific repression in Saccharomyces cerevisiae: Kinetic data on ARG1 and ARG3 mRNA transcription and stability support a transcriptional control mechanism. Mol. Cell. Biol. 1990, 10, 12261233.

(21) Thomas, D.; Surdin-Kerjan, Y. Metabolism of sulfur amino acids in Saccharomyces cerevisiae. Microbiol. Mol. Biol. Rev. 1997, 61, 503-532.

(22) Johannesen, P. F.; Hansen, J. Differential transcriptional regulation of sulfur assimilation gene homologues in the Saccharomyces carlsbergensis yeast species hybrid. FEMS Yeast Res. 2002, 1, 315-322.

(23) Zhao, Z.; Chen, H.; Li, K.; Du, W.; He, S.; Liu, H. W. Reaction of 1-amino-2-methylenecyclopropane-1-carboxylate with 1-aminocyclopropane-1-carboxylate deaminase: analysis and mechanistic implications. Biochemistry 2003, 42, 2089-2103.

(24) Yao, M.; Ose, T.; Sugimoto, H.; Horiuchi, A.; Nakagawa, A.; Wakatsuki, S.; Yokoi, D.; Murakami, T.; Honma, M.; Tanaka, I. Crystal structure of 1-aminocyclopropane-1-carboxylate deaminase from Hansenula saturnus. J. Biol. Chem. 2000, 275, 34557-34565.

(25) Rose, R. B.; Pullen, K. E.; Bayle, J. H.; Crabtree, G. R.; Alber, T. Biochemical and structural basis for partially redundant enzymatic and transcriptional functions of $\mathrm{DCoH}$ and $\mathrm{DCoH} 2$. Biochemistry 2004, 43, 7345-7355.

(26) Kakihara, Y.; Nabeshima, K.; Hirata, A.; Nojima, H. Overlapping omt $1^{+}$and $\mathrm{omt} 2^{+}$genes are required for spore wall maturation in Schizosaccharomyces pombe. Genes Cells 2003, 8, 547-558. 
(27) Pey, A. L.; Martinez, A.; Charubala, R.; Maitland, D. J.; Teigen, K.; Calvo, A.; Pfleiderer, W.; Wood, J. M.; Schallreuter, K. U. Specific interaction of the diastereomers $7(\mathrm{R})$ - and $7(\mathrm{~S})$ tetrahydrobiopterin with phenylalanine hydroxylase: Implications for understanding primapterinuria and vitiligo. FASEB J. 2006, 20, 2130-2132.

(28) Burke, D. J.; Church, D. Protein synthesis requirements for nuclear division, cytokinesis, and cell separation in Saccharomyces cerevisiae. Mol. Cell. Biol. 1991, 11, 3691-3698.

(29) Grundy, F. J.; Henkin, T. M. tRNA as a positive regulator of transcription antitermination in B. subtilis. Cell 1993, 74, 475482.

(30) Grundy, F. J.; Henkin, T. M. Conservation of a transcription antitermination mechanism in aminoacyl-tRNA synthetase and amino acid biosynthesis genes in gram-positive bacteria. $J$. Mol. Biol. 1994, 235, 798-804.

(31) Comer, M. M.; Dondon, J.; Graffe, M.; Yarchuk, O.; Springer, M. Growth rate-dependent control, feedback regulation and steady-state mRNA levels of the threonyl-tRNA synthetase gene of Escherichia coli. J. Mol. Biol. 1996, 261, 108-124.

(32) Maloy, S.; Stewart, V. Autogenous regulation of gene expression. J. Bacteriol. 1993, 175, 307-316.

(33) Frugier, M.; Ryckelynck, M.; Giege, R. tRNA-balanced expression of a eukaryal aminoacyl-tRNA synthetase by an mRNAmediated pathway. EMBO Rep. 2005, 6, 860-865.

(34) Wang, L. W.; Marzluf, G. A. Nitrogen regulation of uricase synthesis in Neurospora crassa. Mol. Gen. Genet. 1979, 176, 385-392.

(35) Geerlof, A.; Travers, F.; Barman, T.; Lionne, C. Perturbation of yeast 3-phosphoglycerate kinase reaction mixtures with ADP: Transient kinetics of formation of ATP from bound 1,3bisphosphoglycerate. Biochemistry 2005, 44, 14948-14955.

(36) Myre, M. A.; O'Day, D. H. Calmodulin binds to and inhibits the activity of phosphoglycerate kinase. Biochim. Biophys. Acta 2004, 1693, 177-183.

(37) Gautan, N. Mutated forms of phosphoglycerate mutase in yeast affect reversal of metabolic flux. Effect of reversible and irreversible function of an enzyme on pathway reversal. J. Biol. Chem. 1988, 263, 15400-15406.

(38) Chen, Y.; Tye, B. K. The yeast $\mathrm{Mcm} 1$ protein is regulated posttranscriptionally by the flux of glycolysis. Mol. Cell. Biol. 1995, 15, 4631-4639.

(39) Rodeheffer, M. S.; Shadel, G. S. Multiple interactions involving the amino-terminal domain of yeast mtRNA polymerase determine the efficiency of mitochondrial protein synthesis. J. Biol. Chem. 2003, 278, 18695-18701.

(40) Erie, D. A. The many conformational states of RNA polymerase elongation complexes and their roles in the regulation of transcription. Biochim. Biophys. Acta 2002, 1577, 224-239.

(41) Lee, G. C.; Tang, S. J.; Sun, K. H.; Shaw, J. F. Analysis of the gene family encoding lipases in Candida rugosa by competitive reverse transcription-PCR. Appl. Environ. Microbiol. 1999, 65, $3888-3895$

(42) Caldon, C. E.; Yoong, P.; March, P. E. Evolution of a molecular switch: universal bacterial GTPases regulate ribosome function. Mol. Microbiol. 2001, 41, 289-297.

(43) Willemoes, M.; Hove-Jensen, B. Binding of divalent magnesium by Escherichia coli phosphoribosyl diphosphate synthetase. Biochemistry 1997, 36, 5078-5083.

(44) Vavassori, S.; Wang, K.; Schweizer, L. M.; Schweizer, M. In Saccharomyces cerevisiae, impaired PRPP synthesis is accompanied by valproate and $\mathrm{Li}^{+}$sensitivity. Biochem. Soc. Trans. 2005, 33, 1154-1157.
(45) Eriksen, T. A.; Kadziola, A.; Larsen, S. Binding of cations in Bacillus subtilis phosphoribosyldiphosphate synthetase and their role in catalysis. Protein Sci. 2002, 11, 271-279.

(46) Kalivoda, K. A.; Steenbergen, S. M.; Vimr, E. R.; Plumbridge, J. Regulation of sialic acid catabolism by the DNA binding protein NanR in Escherichia coli. J. Bacteriol. 2003, 185, 48064815.

(47) Rigali, S.; Derouaux, A.; Giannotta, F.; Dusart, J. Subdivision of the helix-turn-helix GntR family of bacterial regulators in the FadR, HutC, MocR, and YtrA subfamilies. J. Biol. Chem. 2002, 277, 12507-12515.

(48) Charlier, D.; Kholti, A.; Huysveld, N.; Gigot, D.; Maes, D.; ThiaToong, T. L.; Glansdorff, N. Mutational analysis of Escherichia coli PepA, a multifunctional DNA-binding aminopeptidase. $J$. Mol. Biol. 2000, 302, 411-426.

(49) Mathew, Z.; Knox, T. M.; Miller, C. G. Salmonella enterica serovar typhimurium peptidase B is a leucyl aminopeptidase with specificity for acidic amino acids. J. Bacteriol. 2000, 182, 33833393.

(50) Rowen, D. W.; Meinke, M.; LaPorte, D. C. GLC3 and GHA1 of Saccharomyces cerevisiae are allelic and encode the glycogen branching enzyme. Mol. Cell. Biol. 1992, 12, 2229

(51) Wilson, W. A.; Hughes, W. E.; Tomamichel, W.; Roach, P. J. Increased glycogen storage in yeast results in less branched glycogen. Biochem. Biophys. Res. Commun. 2004, 320, 416423.

(52) Chen, L. M.; Li, K. Z.; Miwa, T.; Izui, K. Overexpression of a cyanobacterial phosphoenolpyruvate carboxylase with diminished sensitivity to feedback inhibition in Arabidopsis changes amino acid metabolism. Planta 2004, 219, 440-449.

(53) Ling, H.; Vadali, R. V.; Bennett, G. N.; San, K. Y. Increasing the acetyl-CoA pool in the presence of overexpressed phosphoenolpyruvate carboxylase or pyruvate carboxylase enhances succinate production in Escherichia coli. Biotechnol. Prog. 2004, 20, 1599-1604.

(54) Vienken, K.; Scherer, M.; Fischer, R. The Zn(II)2Cys6 putative Aspergillus nidulans transcription factor repressor of sexual development inhibits sexual development under low-carbon conditions and in submersed culture. Genetics 2005, 169, 619630.

(55) Ross, K. L.; Davis, C. N.; Fridovich-Keil, J. L. Differential roles of the Leloir pathway enzymes and metabolites in defining galactose sensitivity in yeast. Mol. Genet. Metab. 2004, 83, 103116.

(56) Klar, A. J.; Cohen, A.; Halvorson, H. O. Control of enzyme synthesis and stability during sporulation in Saccharomyces cerevisiae. Biochimie 1976, 58, 219-224.

(57) Takagi, M.; Kawai, S.; Shibuya, I.; Miyazaki, M.; Yano, K. Cloning in Saccharomyces cerevisiae of a cycloheximide resistance gene from the Candida maltosa genome which modifies ribosomes. J. Bacteriol. 1986, 168, 417-419.

Received for review January 19, 2007. Revised manuscript received April 27, 2007. Accepted May 1, 2007.

JF070162F 